\title{
Transfer-consultations for young people: how do we do?
}

\author{
G Teilmann, K Boisen, J Pødenphant, M Zak, S Nielsen \\ From 18th Pediatric Rheumatology European Society (PReS) Congress \\ Bruges, Belgium. 14-18 September 2011
}

\section{Background}

The need of well-planned transition programmes for young people is well established, and there is growing evidence of the benefits in terms of increased health realted quality of life, better disease knowledge and patient satisfaction. However, we still need a better understanding of the optimal models and the outcomes of establishing such activities.

\section{Aim}

To establish well-planned transfer-consultations for young people with rheumatic diseases to ensure youthfriendly uninterrupted health care provision and evaluate the outcomes.

\section{Methods}

A mini-survey $(\mathrm{N}=10)$ and two individual interviews was conducted among young patients in the pediatric outpatient clinic to explore the young peoples wishes for a youth-friendly daily praxis as well as wishes concerning transfer to the adult department. Based on these experiences we introduced shared transfer-consultations in collaboration between rheumatologists from the pediatric and the adult department for adolescents with rheumatic diseases as a pilot-project. Participants in the transfer consultaions were the young patient as well as a rheumatologist from the pediatric (SN/MZ) and the adult department (JP). 30 adolescents have participated so far.

\section{Results}

Feed-back from young patients and doctors during the pilot-phase has over-all been positive. The pilot phase has demonstrated a need for involving young people in the planning process. We are currently developing youth friendly information material about transfer from pediatric to adult rheumatolgy as well as a written policy for transfer. In addition a systematic evaluation of the transfer-consultations is needed. Results from semistructured interviews with adolescents and doctors who have participated in a transfer-consultation will take place in May-August 2011 and will be presented at the conference.

\section{Conclusion}

Young patients and doctors are positive towards shared transfer-consultations. Involving young people in the planning proces has shown to be fruitful. A written policy and a systematic evalutation is under preparation.

Published: 14 September 2011

doi:10.1186/1546-0096-9-S1-P272

Cite this article as: Teilmann et al:: Transfer-consultations for young people: how do we do? Pediatric Rheumatology 2011 9(Suppl 1):P272. and take full advantage of:

- Convenient online submission

- Thorough peer review

- No space constraints or color figure charges

- Immediate publication on acceptance

- Inclusion in PubMed, CAS, Scopus and Google Scholar

- Research which is freely available for redistribution

\section{Biomed Central}

(c) 2011 Teilmann et al; licensee BioMed Central Ltd. This is an open access article distributed under the terms of the Creative Commons Attribution License (http://creativecommons.org/licenses/by/2.0), which permits unrestricted use, distribution, and reproduction in any medium, provided the original work is properly cited. 